$12-2009$

Psychological well-being and socio-economic hardship among AIDS orphans and other vulnerable children in Guinea

Wim Delva

An Vercoutere

Catherine Loua

Cathérine Loua

Jonas Lamah

See next page for additional authors

Follow this and additional works at: https://ecommons.aku.edu/eastafrica_fhs_mc_obstet_gynaecol

Part of the Other Mental and Social Health Commons 
Authors

Wim Delva, An Vercoutere, Catherine Loua, Cathérine Loua, Jonas Lamah, Stijn Vansteelandt, Petra de Koker, Patricia Claeys, Marleen Temmerman, and Lieven Annemans 
archives-ouvertes

\title{
Psychological well-being and socio-economic hardship among AIDS orphans and other vulnerable children in Guinea
}

\author{
Wim Delva, An Vercoutere, Cathérine Loua, Jonas Lamah, Stijn \\ Vansteelandt, Petra de Koker, Patricia Claeys, Marleen Temmerman, Lieven
}

Annemans

\section{To cite this version:}

Wim Delva, An Vercoutere, Cathérine Loua, Jonas Lamah, Stijn Vansteelandt, et al.. Psychological well-being and socio-economic hardship among AIDS orphans and other vulnerable children in Guinea. AIDS Care, Taylor \& Francis (Routledge), 2009, 21 (12), pp.1490-1498. 10.1080/09540120902887235 . hal-00545379

\section{HAL Id: hal-00545379 \\ https://hal.archives-ouvertes.fr/hal-00545379}

Submitted on 10 Dec 2010

HAL is a multi-disciplinary open access archive for the deposit and dissemination of scientific research documents, whether they are published or not. The documents may come from teaching and research institutions in France or abroad, or from public or private research centers.
L'archive ouverte pluridisciplinaire HAL, est destinée au dépôt et à la diffusion de documents scientifiques de niveau recherche, publiés ou non, émanant des établissements d'enseignement et de recherche français ou étrangers, des laboratoires publics ou privés. 

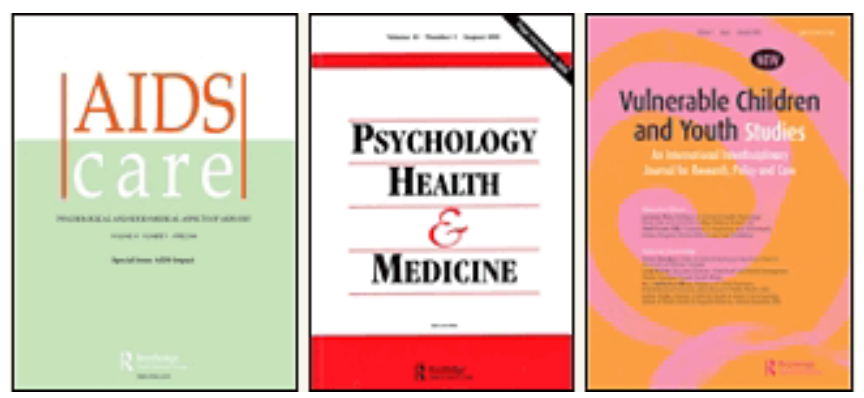

\section{Psychological well-being and socio-economic hardship among AIDS orphans and other vulnerable children in Guinea}

\begin{tabular}{|r|l|}
\hline Journal: & $\begin{array}{l}\text { AIDS Care - Psychology, Health \& Medicine - Vulnerable Children } \\
\text { and Youth Studies }\end{array}$ \\
\hline Manuscript ID: & AC-2008-07-0326.R1 \\
\hline Journal Selection: & AIDS Care \\
\hline Keywords: & AIDS, orphans, Guinea, West-Africa \\
\hline
\end{tabular}

\section{今 scholaroNE" \\ Manuscript Central}




\title{
Psychological well-being and socio-economic hardship among AIDS orphans and other vulnerable children in Guinea
}

\section{Running Head: AIDS orphans and other vulnerable children in Guinea}

Keywords: AIDS, orphans, psychological well-being, school attendance, Guinea, West Africa

\begin{abstract}
Over the past decade, the effects of AIDS-related parental death on children's socioeconomic, educational and psychological well-being have become apparent. Most studies, however, have compared the plight of so-called AIDS orphans with nonorphaned children only. Consequently, such study designs are unable to establish if the AIDS-related cause of death of the parents confers effects additional to those of parentbereavement. We therefore conducted a cross-sectional survey to assess the psychological well-being and socio-economic hardship among 140 non-orphaned children, 133 children orphaned by causes other than AIDS and 124 children orphaned by AIDS in Conakry, N'Zérékoré and the villages around N'Zérékoré, Guinea. Multi-way analysis of variance and multiple (ordinal) logistic regression models were applied to measure the association between the orphan status and psychological well-being, school attendance, economic activities, frequency of going to bed hungry and sleeping
\end{abstract}


commodity. After adjustment for confounding factors, the psychological well-being score was significantly lower among AIDS-orphaned children than among children orphaned by causes other than AIDS ( $\mathrm{P}<0.001)$. Additionally, AIDS-orphaned children were more likely to be engaged in economic activities (adjusted odds ratio $(\mathrm{AOR})=3.04 ; 95 \% \mathrm{CI}$ : $1.45-6.36)$ and to go to bed hungry on a daily basis (AOR $=2.73 ; 95 \% \mathrm{CI}: 1.24-6.02)$ than other orphans. The differences in school attendance and the proportion of children with a bed or couch to sleep between AIDS-orphaned children and children orphaned by causes other than AIDS were not statistically significant. This situation calls for sustainable and holistic approaches to ensure the psychological and socio-economic stability of AIDS orphans and other vulnerable children.

Keywords: AIDS, orphans, psychological well-being, school attendance, Guinea, West Africa

Word count: 3468 words 


\section{INTRODUCTION}

In Guinea $0.9 \%$ of men and $1.9 \%$ of women between 15 and 49 years of age were estimated to be HIV positive in 2005 (Direction Nationale de la Statistique (Guinée) \& ORC Macro, 2006). Although this estimate is low compared to the HIV prevalence in other parts of sub-Saharan Africa, large socio-demographical differences exist with HIV prevalence rates as high as $42 \%$ having been observed among female sex workers (Diakité, 2007). Additionally in N'Zérékoré, which is characterized by intensive immigration and emigration due to its close location to the borders with civil war stricken Liberia, Sierra Leone and Ivory Coast, an HIV prevalence of 7\% was observed among pregnant women in 2001 (Barry, Kaba, \& Diop, 2002). Thus, one decade of conflict combined with an established HIV epidemic in this region of West-Africa has resulted in an estimated 370000 orphans living in Guinea in 2005, of which 28000 are the result of AIDS (UNICEF, 2006).

Over the past decade, it has become clear that children of whom one or both parents are known to be HIV positive or have died of AIDS, are especially vulnerable. They bear more socio-economic hardship, are less likely to be at the proper education level, feel more frequently stigmatized and discriminated against and carry a heavier psychological burden than children of parents that are alive and not affected by HIV/AIDS (Bauman, Foster, Silver, Berman, Gamble, \& Muchaneta, 2006; Cluver \& Gardner, 2007; Forehand, Steele, Armistead, Morse, Simon, \& Clark, 1998; Funkquist, Eriksson, \& Muula, 2007; He \& Ji, 2007; Lee, Detels, Rotheram-Borus, Duan, \& Lord, 2007; Nyamukapa, Gregson, Lopman, Saito, Watts, Monasch et al., 2008; Rotheram-Borus, 
Stein, \& Lin, 2001; Rotheram-Borus, Weiss, Alber, \& Lester, 2005; Strode \& BarrettGrant, 2001). Most studies, however, have compared the plight of so-called AIDSorphans with non-orphaned children only. Consequently, such study designs, which leave out a comparison group of children orphaned by causes other than AIDS, are unable to establish if the AIDS-related cause of death of the parent(s) confers effects additional to those of parent-bereavement (Wild, Flisher, Laas, \& Robertson, 2006).

In order to address this research gap, we conducted a cross-sectional survey assessing the psychological well-being, socio-economic hardship and perceived support among nonorphaned, non-AIDS-affected children (NO), children orphaned by causes other than AIDS (O), non-orphaned, AIDS-affected children (NO-A) and children orphaned by AIDS (O-A) in Conakry, N'Zérékoré and the villages around N'Zérékoré.

\section{METHODS}

In August - September 2006 a cross-sectional survey was conducted among 397 children aged 10 to 18 years in the regions of Conakry and N'Zérékoré, Guinea. Specifically, a total of twelve quarters from the five districts of Conakry were selected. In the city centre of N'Zérékoré, 19 quarters were selected. Additionally, we recruited children from five villages in the proximity of N'Zérékoré where international humanitarian organizations such as the World Food Programme and PLAN International are highly active. The identification and categorization of the children was driven by the perception of the community of the quarter. Key informants from local authorities and local nongovernmental and community-based organizations (NGOs and CBOs) were asked to 
identify households with children belonging to three distinct categories. The first category was comprised of children whose parents were still alive and not perceived to be HIV positive (NO). The second category consisted of parentally-bereaved children, whereby the parental death was thought not to be HIV/AIDS-related (O). The last category contained children who were said to have lost one or both parents to AIDS (OA). Subsequently, household visits were organized, during which the perceived orphan status was confirmed by asking the children of household about the cause of death of the parent(s) and/or if any of the parents were infected with HIV. Their answers were verified with the members of the household that the children were living in at the moment of the interview, as well as with neighbours and other members of the direct community that the household was situated in. In 20 cases, the views on the cause of parental death were conflicting and these cases were excluded from the analysis. Another 39 households (2 NO, $19 \mathrm{O}$ and $18 \mathrm{O}-\mathrm{A})$ refused to participate. We used purposive quota sampling techniques to recruit children in each region. The number of children to be interviewed in each quarter or village was proportional to the number of inhabitants of that area (based on the 2006 census). All children had to be aged 10-18 years and a maximum of two children were interviewed per household.

A structured questionnaire was developed, based upon standardized questionnaires used by the Horizons Program, Family Health International and the International Center for Research on Women in Zimbabwe, Uganda, Zambia and Tanzania and translated into French by a local humanitarian organization (FELICA) (Gilborn, Apicella, Brakarsh, Dube, Jemison, Kluckow et al., 2006; Gilborn, Nyonyintono, Kabumbuli, \& Jagwe- 
Wadda, 2001; Tanzania Stigma-Indicators Field Test Group, 2005; Tembo \& Banda, 2002). After having explained the study objectives to each candidate respondent, informed consent to participate in the survey was obtained from the child and one of his/her parents or foster care givers. Multiple choice questions covered sociodemographic information, indicators of psychological well-being (difficulties falling asleep, feeling safe in daily life, difficulties in concentrating, being scared sometimes, frequency of crying, frequency of worrying and feeling good about oneself: cfr. appendix), stigmatization and discrimination, social networking with peers, socioeconomic hardship and the perceived levels of support from family members, outsiders, the community in general and the religious community. The study protocol was approved by the ethical committee of the Ghent University, Belgium (project number $\mathrm{EC} / 2006 / 160)$.

For this paper, we considered data pertaining to psychological well-being, school attendance, engagement in child labour, frequency of hunger and sleeping commodity. Data analysis was performed with $\mathrm{R}$ version 2.4.1 (Ihaka \& Gentleman, 1996; R Development Core Team, 2005). A psychological well-being score (PWS) was generated by taking the sum of the individual scores for the separate indicators of psychological well-being, such that a higher PWS represents a better psychological well-being. Cronbach's alpha was computed to measure the consistency among the individual items of the PWS. The potentially confounding effects of age, sex, religion, region and number of minors in the household on the association between orphan status and PWS were assessed via multi-way analysis of variance (ANOVA) models. Multiple ordinal logistic 
regression models were fitted to measure the associations between the orphan status and school attendance, economic activities, frequency of going to bed hungry, and sleeping commodity. Tukey's method (for ANOVA) and the Dunn-Ŝidák method (for logistic regression) were used to correct for multiple comparison testing.

\section{RESULTS}

A total of 397 children between 10 and 18 years of age were surveyed, of which 193 originated from Conakry, 115 from the city centre of N'Zérékoré and the remaining 89 from the villages around N'Zérékoré. The distributions of age, sex and number of minors living in the household were not significantly different between the three groups of children, although O-A were more frequently living in large households (cfr. Table 1). Religious beliefs were unequally distributed with markedly less Christian children among NO-A and O-A $(\mathrm{P}=0.01)$. The head of household was different for orphaned and nonorphaned children $(\mathrm{P}=0.002)$, with orphans more frequently being raised by grandparents or extended family members. The proportion of children who had lost both parents (double orphans) was significantly higher among AIDS orphans than among the children orphaned by causes other than AIDS.

\section{Psychological well-being}

For each of the seven validated indicators of psychological well-being, the NO scored better than $\mathrm{O}$, which in turn had higher scores than the O-A. Chi-square tests comparing the $\mathrm{O}$ and $\mathrm{O}-\mathrm{A}$, showed only significant differences at the alpha level of 0.05 for three indicators: Feeling safe in daily life, frequency of crying and feeling good about oneself. 
The seven indicators of psychological well-being were combined into an overall score of psychological well-being ranging from 0 to 14 . Cronbach's alpha was 0.73 indicating acceptable internal consistency, given the small number of items that the score consists of. In the one-way ANOVA model, the mean PWS for O was 5.3 (95\% CI: 4.8 - 5.8). The average score for NO was $2.5(95 \% \mathrm{CI}: 1.8-3.2)$ higher than that of O, while O-A scored on average 1.7 (95\% CI: 1.0 - 2.5) lower. Figure 1 displays how the PSW differed by orphan status.

In the final multi-way ANOVA model, the child's orphan status $(\mathrm{P}<0.001)$, the region of origin $(\mathrm{P}<0.001)$ and the number of minors living in the household $(\mathrm{P}<0.001)$ were independently associated with the PWS (cfr. Table 2). NO had a significantly higher PWS than the other children $(\mathrm{P}<0.001)$. Further, $\mathrm{O}$ scored higher than $\mathrm{O}-\mathrm{A}(\mathrm{P}<0.001)$. Among children with the same orphan status, lower scores were measured in Conakry than in the city centre of N'Zérékoré and the five villages surrounding N'Zérékoré $(\mathrm{P}<$ 0.001). Finally, living with 7 or more children in one household conferred an additional negative effect on the PSW.

\section{Socio-economic hardship}

School attendance, economic activities, the frequency of going to bed hungry and the sleeping commodity were assessed for all children so as to sketch the conditions under which these children are being raised. Identification of differences children orphaned by causes other than AIDS and AIDS-orphaned children was of primary interest in the analyses. Odds ratios were adjusted for age, sex, region, religion and the number of 
minors living in the household, when these variables were associated with the outcome of interest and therefore potentially confounded the association between orphan status and the outcome (cfr. Table 3).

Observed rates of daily school attendance were $73.6 \%(103 / 140)$ for NO, $47.4 \%(63 / 133)$ for $\mathrm{O}$ and $41.9 \%(52 / 124)$ for O-A. Besides differential school attendance rates across orphan status groups, boys were significantly more likely to go to school on a daily basis than girls $(59.6 \%(137 / 230)$ versus $48.5 \%(81 / 167)$ respectively; $\mathrm{P}=0.04)$. Although the proportional odds ratio for school attendance, adjusted for sex, in $\mathrm{O}-\mathrm{A}$ versus $\mathrm{O}$ was not significantly different from $1(\mathrm{P}=0.34)$, a trend of decreased school attendance could be observed among AIDS-orphans, especially in girls (cfr. figure 2).

\section{Economic activities}

While $39.3 \%(55 / 140)$ of $\mathrm{NO}$ and $46.6 \%(62 / 133)$ of $\mathrm{O}$ were involved in some kind of economic activities, much higher rates of economically active children were observed among O-A $(71.8 \%(89 / 124))(\mathrm{P}<0.001)$. Most economic activities in Conakry and the city centre of N'Zérékoré concerned petty trading. In the rural villages around N'Zérékoré, children were mostly working as farmers and domestic workers. Multiple logistic regression analysis revealed that not only the child's orphan status $(\mathrm{P}<0.001)$ but also his/her religion $(\mathrm{P}<0.001)$ and region $(\mathrm{P}<0.001)$ were independently associated with engagement in economic activities. Children orphaned by AIDS were more likely to be economically active than children orphaned by causes other than AIDS (AOR = 3.00; 95\% CI: $1.39-6.45)$ as were children who reported not to have a Christian or Muslim 
religion $(\mathrm{AOR}=37.78 ; 95 \% \mathrm{CI}: 2.13-670.09)$. Living in the rural villages around N'Zérékoré conferred protective effects on child labour $(\mathrm{AOR}=0.32 ; 95 \% \mathrm{CI}: 0.12$ $0.83)$.

\section{Hunger}

Figure 3 points out that the differences in frequencies of going to bed hungry across orphan status groups are primarily situated at the level of daily hunger. We therefore recoded the "hunger" variable into a dichotomous indicator of whether or not the child reported to go to bed hungry on a daily basis. While $15.7 \%(22 / 140)$ of NO children reported to do so, these proportions were $27.8 \%$ (37/133) among $\mathrm{O}$ and $46.0 \%(57 / 124)$ among O-A. After adjusting for region and religion, O-A were still more likely to face daily hunger than $\mathrm{O}(\mathrm{P}=0.005)$, who in turn were more at risk of daily hunger compared to NO $(\mathrm{P}=0.04)$. Furthermore, children in Conakry were much more likely to go to bed hungry on a daily basis than children from the other regions $(\mathrm{P}<0.001)$.

\section{Sleeping commodity}

Almost half of the NO (68/140) reported having a bed or a couch to sleep on. This was only true for $35.3 \%(47 / 133)$ of $\mathrm{O}$ and $37.9 \%$ (47/124) of O-A. After adjusting for religion, region, age and number of minors in the household, O-A were as frequently deprived of an ample sleeping commodity as $\mathrm{O}(\mathrm{AOR}=0.99 ; 95 \% \mathrm{CI}: 0.41-2.37)$. Living in Conakry $(\mathrm{P}<0.001)$, younger age $(\mathrm{P}=0.004)$, living in a household with more than 9 minors $(\mathrm{AOR}=3.76$; $95 \% \mathrm{CI}$ : $1.05-13.48)$ were identified as additional risk factors for not having a bed or couch to sleep on. 


\section{DISCUSSION}

The research findings outlined in this paper were presented and discussed during a national conference in early September 2007 in Conakry, attended by representatives of local, national and international NGOs and donor organizations, and chaired by the president of the national commission for the fight against HIV and AIDS (CNLS). During this conference, recommendations were formulated in response to the obvious psychological and socio-economic vulnerability of children affected by AIDS. A first call for action was based on the clear need for psychological and social support for AIDSorphaned children. We reached the same conclusion as that of a recent study which showed so called AIDS-orphans to be more psychologically distressed than children orphaned by causes other than AIDS (Cluver, Gardner, \& Operario, 2007). The graphical representation of the PWS data further indicates that, although O-A generally had a lower PWS than NO and O, low scores were observed for at least some individuals in all categories. We therefore concur with Meintjes and Giese that any attempt to improve the psychological and social support for AIDS-affected children should be embedded in a holistic, rights-based approach applicable to all children rather than "affirmative action" only geared towards AIDS-orphaned children. The latter may be conducive to stigmatization and discrimination of AIDS-orphaned children and entails a risk of reduced focus and efforts for other groups of vulnerable children (Meintjes \& Giese, 2006). Support focused on large households in which seven or more minors are living should be considered as a complementary strategy in addition to existing programmes for delivery of foster care and support as this may help to reach other vulnerable children that 
are not necessarily orphaned or living with HIV infected parents. Finally, our results show that the psychological well-being of children in Conakry is more likely to suffer than that of children in N'Zérékoré and its surrounding villages, where international humanitarian organizations such as the World Food Programme and PLAN International are known to be highly active. Our study design does not permit however, to infer a causal relationship between the donor support received in these Southern regions of Guinea and a relatively higher psychological well-being. To this end, further research, preferably using a cluster-randomised controlled trial design, would be needed. Similarly, the effects of donor support on the nutritional status in communities targeted by humanitarian organizations should be investigated as well.

As reported in many other countries, daily school attendance rates in our study sample were lower among orphans than among non-orphaned children (Makame, Ani, \& Grantham-McGregor, 2002; Mishra, Arnold, Otieno, Cross, \& Hong, 2007; Monasch \& Boerma, 2004; Oleke, Blystad, Fylkesnes, \& Tumwine, 2007). This observation coincides with high levels of economic activities, especially among AIDS-orphaned children. However, despite being much more involved in economic activities, they were still significantly more likely to go to bed hungry than non-AIDS orphans and nonorphaned children. These findings portray the harsh living conditions of children affected by AIDS and other vulnerable children in Guinea. The high frequency of going to bed hungry reflects the aggravated poverty in HIV/AIDS affected households in this setting, as is the case in other countries in sub-Saharan Africa (Bachmann \& Booysen, 2004; Booysen, 2004; Collins \& Leibbrandt, 2007; Hosegood, Preston-Whyte, Busza, Moitse, 
\& Timaeus, 2007; Rajaraman, Russell, \& Heymann, 2006). The subsequent urge to generate a living, associated with irregular or no school attendance is likely to impede the attainment of scholastic knowledge and the development of life skills (Case, Paxson, \& Ableidinger, 2004). Our study also confirmed previous evidence from Guinea and other sub-Saharan countries that girls and children living in larger households are experiencing additional barriers to school attendance, regardless of orphan status and parental cause of death (Blum, 2007; Glick \& Sahn, 2000; Togunde \& Richardson, 2006). Hence, alternative approaches are needed in addition to the existing responses in order to address the rights to education for children living in impoverished and/or HIV/AIDS affected households. Scaling up of antiretroviral treatment programmes will help parents living with HIV/AIDS to stay healthy and economically active for a longer time, thereby avoiding or delaying school drop-out of their children. Community schools have been established in a number of African countries (Mali, Malawi, Uganda, and Zambia), offering informal education through voluntary teachers and without school fees and uniforms. However, the quality of education using volunteer teachers may not be optimal and the teachers may leave in search of teaching posts which offer an income, thus jeopardizing the sustainability of this approach (The World Bank, 2002). Guiding poor households in successfully applying for micro financing credit has been associated with a maintenance or even an increase in the household income and a reduction of the household's vulnerability to financial loss (Hepburn, 2001; Sherer, Bronson, Teter, \& Wykoff, 2004). Motivated by a similar rationale, loans for vocational training are likely to bring quick returns if they are provided in close partnerships with the private sector 
and matched to the demand in the labour markets (Marchat, Nasir, Ramachandran, Shah, Tyler, \& Zhao, 2001).

While this study adds to the rapidly increasing evidence of the detrimental effects of parental AIDS death on the psychological well-being and development of children, a detailed situational analysis of the magnitude and nature of the problems related to AIDSaffected children in Guinea, as well as a national strategy and scaled-up interventions are sorely lacking in Guinea. On a positive note, the national conference in September 2007 during which the above research findings were disseminated, evidenced the multiplicity of actors in the field working with HIV/AIDS affected households, orphans and other vulnerable children. Synergy between researchers, NGOs, CBOs, donor organizations and policy makers will be essential as a first priority to conduct a national household survey to verify the extent to which our findings can be generalized to the whole of Guinea. Shisana and Louw have described a research-led policy making process in South Africa, characterized by yearly meetings for public dialogue among the ministers of social development, researchers, NGOs, CBOs and donors on the key issues emanating from research, which resulted in a policy framework for orphans and other children made vulnerable by HIV and AIDS, as well as an action plan in order to operationalize the policy (Shisana \& Louw, 2006). Another example of successful multi-level collaboration is the Children in Need Network (CHIN). The network consists of NGOs, CBOs, and Government Departments that provide information and training to the 70 member organizations, mostly small, community organizations in Zambia that are serving the needs of orphaned or vulnerable children (Sommers, 2003). 
There are two potential limitations of our survey that should be mentioned. Firstly, the survey only included seven indicators of psychological well-being, and they focused on internalising problems rather than conduct problems. Similarly, we only registered four variables to describe the socio-economic environment in which children were being raised. Secondly, all analyses were based upon the perception of the community about the HIV status and/or cause of death of the children's parent(s). While this may have lead to classification errors, we argue that the meaning and implications of our findings are still relevant, especially in settings where few people know their HIV status and the community's attitudes and behaviours towards children (both supportive and discriminatory actions) are guided by perceptions rather than facts. As we were mainly interested in the full effect that orphan status $(\mathrm{O} / \mathrm{O}-\mathrm{A})$ had on outcome variables (so including the indirect effect that is mediated by single/double orphanhood), and not just in the direct effect, we did not need to control for double/single orphanhood. An advantage of the resulting analysis is that it is valid, even if there were confounders of the causal association between double versus single orphanhood and the outcome variables (Cole \& Hernán, 2002).

In conclusion, our results suggest that the psychological health of children who are thought to be AIDS-orphaned is more threatened than that of other orphans. Additionally, AIDS orphans were significantly more likely to go to bed hungry than non-AIDS orphans in Guinea despite being much more involved in economic activities. Low psychosocial well-being scores and unfavourable socio-economic living conditions were also observed 
for at least some non-orphans and non-AIDS orphans. Comprehensive, nondiscriminatory strategies involving all stakeholders in the fields of health and social development are therefore urgently needed.

\section{REFERENCES}

Bachmann, M.O., \& Booysen, F.L. (2004). Relationships between HIV/AIDS, income and expenditure over time in deprived South African households. AIDS Care, 16(7), 817826.

Barry, A., Kaba, D., \& Diop, I. (2002). Rapport Final ESSIDAGUI/2001: STAT-VIEW International.

Bauman, L., Foster, G., Silver, E., Berman, R., Gamble, I., \& Muchaneta, L. (2006). Children caring for their ill parents with HIV/AIDS. Vulnerable Children and Youth Studies, 1(1), 56-70.

Blum, R.W. (2007). Youth in sub-Saharan Africa. J Adolesc Health, 41(3), 230-238. Booysen, F. (2004). Social grants as safety net for HIV/AIDS-affected households in South Africa. Sahara J, 1(1), 45-56.

Case, A., Paxson, C., \& Ableidinger, J. (2004). Orphans in Africa: parental death, poverty, and school enrollment. Demography, 41(3), 483-508.

Cluver, L., \& Gardner, F. (2007). The mental health of children orphaned by AIDS: a review of international and southern African research. Journal of Child and Adolescent Mental Health, 19(1), 1-17.

Cluver, L., Gardner, F., \& Operario, D. (2007). Psychological distress amongst AIDSorphaned children in urban South Africa. J Child Psychol Psychiatry, 48(8), 755-763. 
Cole, S.R., \& Hernán, M.A. (2002). Fallibility in estimating direct effects. Int J Epidemiol, 31(1), 163-165.

Collins, D.L., \& Leibbrandt, M. (2007). The financial impact of HIV/AIDS on poor households in South Africa. Aids, 21 Suppl 7, S75-81.

Diakité, M. (2007). Personal communication. Conakry.

Direction Nationale de la Statistique (Guinée), \& ORC Macro (2006). Enquête

Démographique et de Santé Guinée 2005.: DNS \& ORC Macro.

Forehand, R., Steele, R., Armistead, L., Morse, E., Simon, P., \& Clark, L. (1998). The

Family Health Project: psychosocial adjustment of children whose mothers are HIV infected. J Consult Clin Psychol, 66(3), 513-520.

Funkquist, A., Eriksson, B., \& Muula, A.S. (2007). The vulnerability of orphans in Thyolo District, southern Malawi. Tanzan Health Res Bull, 9(2), 102-109.

Gilborn, L., Nyonyintono, R., Kabumbuli, R., \& Jagwe-Wadda, G. (2001). Making a Difference for Children Affected by AIDS: Baseline Findings from Operations Research in Uganda. Washington DC: Population Council.

Gilborn, L., Apicella, L., Brakarsh, J., Dube, L., Jemison, K., Kluckow, M., Smith, T., \& Snider, L. (2006). Orphans and vulnerable youth in Bulawayo, Zimbabwe: An exploratory study of psychosocial well-being and psychosocial support programs. Horizons Final Report 2006. Washington DC: Population Council.

Glick, P., \& Sahn, D.E. (2000). Schooling of girls and boys in a West African country: the effects of parental education, income, and household structure. Econ Educ Rev, 19(1), $63-87$. 
He, Z., \& Ji, C. (2007). Nutritional status, psychological well-being and the quality of life of AIDS orphans in rural Henan Province, China. Trop Med Int Health, 12(10), 11801190.

Hepburn, A. (2001). Primary Education in Eastern and Southern Africa: Increasing Access for Orphans and Vulnerable Children in AIDS-Affected Areas. Washington DC: Displaced Children and Orphans Fund.

Hosegood, V., Preston-Whyte, E., Busza, J., Moitse, S., \& Timaeus, I.M. (2007). Revealing the full extent of households' experiences of HIV and AIDS in rural South Africa. Soc Sci Med, 65(6), 1249-1259.

Ihaka, R., \& Gentleman, R. (1996). R: A language for data analysis and graphics. Journal of Computational and Graphical Statistics, 5(3), 299-314.

Lee, S.J., Detels, R., Rotheram-Borus, M.J., Duan, N., \& Lord, L. (2007). Depression and social support among HIV-affected adolescents. AIDS Patient Care STDS, 21(6), 409417.

Makame, V., Ani, C., \& Grantham-McGregor, S. (2002). Psychological well-being of orphans in Dar El Salaam, Tanzania. Acta Paediatr, 91(4), 459-465.

Marchat, J.M., Nasir, J., Ramachandran, V., Shah, M.K., Tyler, G., \& Zhao, L. (2001). Results of the Nigeria firm survey. Washington DC: The World Bank. Meintjes, H., \& Giese, S. (2006). Spinning the epidemic: the making of mythologies of orphanhood in the context of AIDS.

Childhood, 13(3), 407-430. 
Mishra, V., Arnold, F., Otieno, F., Cross, A., \& Hong, R. (2007). Education and nutritional status of orphans and children of HIV-infected parents in Kenya. AIDS Educ Prev, 19(5), 383-395.

Monasch, R., \& Boerma, J.T. (2004). Orphanhood and childcare patterns in sub-Saharan Africa: an analysis of national surveys from 40 countries. Aids, 18 Suppl 2, S55-65. Nyamukapa, C.A., Gregson, S., Lopman, B., Saito, S., Watts, H.J., Monasch, R., \& Jukes, M.C. (2008). HIV-associated orphanhood and children's psychosocial distress: theoretical framework tested with data from Zimbabwe. Am J Public Health, 98(1), 133141.

Oleke, C., Blystad, A., Fylkesnes, K., \& Tumwine, J.K. (2007). Constraints to educational opportunities of orphans: a community-based study from northern Uganda. AIDS Care, 19(3), 361-368.

R Development Core Team (2005). R: a language and environment for statistical computing. Vienna: R Foundation for Statistical Computing.

Rajaraman, D., Russell, S., \& Heymann, J. (2006). HIV/AIDS, income loss and economic survival in Botswana. AIDS Care, 18(7), 656-662.

Rotheram-Borus, M.J., Stein, J.A., \& Lin, Y.Y. (2001). Impact of parent death and an intervention on the adjustment of adolescents whose parents have HIV/AIDS. J Consult Clin Psychol, 69(5), 763-773.

Rotheram-Borus, M.J., Weiss, R., Alber, S., \& Lester, P. (2005). Adolescent adjustment before and after HIV-related parental death. J Consult Clin Psychol, 73(2), 221-228. 
Sherer, R.D., Jr., Bronson, J.D., Teter, C.J., \& Wykoff, R.F. (2004). Microeconomic loans and health education to families in impoverished communities: implications for the HIV pandemic. J Int Assoc Physicians AIDS Care (Chic Ill), 3(4), 110-114.

Shisana, O., \& Louw, J. (2006). Translating research into policy: the case of orphans and vulnerable children in South Africa. Sahara J, 3(2), 450-456.

Sommers, T. (2003). Community Schools and Care for AIDS Orphans: Effective Interventions for Vulnerable Children, The School for International Training. Geneva: Wellesley College.

Strode, A., \& Barrett-Grant, K. (2001). The role of stigma and discrimination in increasing the vulnerability of children and youth infected with and affected by HIV/AIDS - Research report. Arcadia: Save the Children.

Tanzania Stigma-Indicators Field Test Group (2005). WORKING REPORT MEASURING HIV STIGMA: RESULTS OF A FIELD TEST IN TANZANIA. Washington DC: USAID.

Tembo, S., \& Banda, A. (2002). Results of the Orphans and Vulnerable Children Head of Household Baseline Survey in Four Districts in Zambia: RuralNet Associates Ltd. University of Zambia.

The World Bank (2002). Education and HIV/AIDS: Ensuring Education Access for Orphans and Vulnerable Children. Washington DC.

Togunde, D., \& Richardson, S. (2006). Household size and composition as correlates of child labour in urban Nigeria. Africa Development, 31(1), 50-65.

UNICEF (2006). The State of the World's Children 2007. New York. 
Wild, L., Flisher, A., Laas, S., \& Robertson, B. (2006). The psychosocial adjustment of Adolescents orphaned in the context of HIV/AIDS. Manuscript submitted for publication. 


\section{APPENDIX}

\begin{tabular}{|c|c|c|c|}
\hline Indicator of psychological well-being & Response & Score & Source \\
\hline $\begin{array}{l}\text { Do you have difficulties falling asleep? } \\
\text { [As-tu des problèmes pour trouver à coucher?] }\end{array}$ & $\begin{array}{l}\text { Yes } \\
\text { No }\end{array}$ & $\begin{array}{l}0 \\
1\end{array}$ & Gilborn et al. 2006 \\
\hline $\begin{array}{l}\text { Do you feel safe in your daily life? } \\
\text { [Tu te sens en sécurité dans ta vie?] }\end{array}$ & $\begin{array}{l}\text { Yes } \\
\text { No }\end{array}$ & $\begin{array}{l}1 \\
0\end{array}$ & Gilborn et al. 2006 \\
\hline $\begin{array}{l}\text { Do you have difficulties in concentrating? } \\
\text { [Est-ce que tu as des problèmes pour se concentrer?] }\end{array}$ & $\begin{array}{l}\text { Yes } \\
\text { No }\end{array}$ & $\begin{array}{l}0 \\
1\end{array}$ & Gilborn et al. 2006 \\
\hline $\begin{array}{l}\text { Are you scared sometimes? } \\
\text { [Est-ce que tu as peur de temps en temps?] }\end{array}$ & $\begin{array}{l}\text { Yes } \\
\text { No }\end{array}$ & $\begin{array}{l}0 \\
1\end{array}$ & Tembo \& Banda 2002 \\
\hline $\begin{array}{l}\text { Do you cry... } \\
\text { [Est-ce que tu pleures...] }\end{array}$ & $\begin{array}{l}\text { Often } \\
\text { Sometimes } \\
\text { Rarely } \\
\text { Never }\end{array}$ & $\begin{array}{l}0 \\
1 \\
2 \\
3\end{array}$ & Gilborn et al. 2001 \\
\hline $\begin{array}{l}\text { Do you have worries? } \\
\text { [As-tu des soucis?] }\end{array}$ & $\begin{array}{l}\text { Often } \\
\text { Sometimes } \\
\text { Rarely } \\
\text { Never }\end{array}$ & $\begin{array}{l}0 \\
1 \\
2 \\
3\end{array}$ & Tembo \& Banda 2002 \\
\hline $\begin{array}{l}\text { Do you feel good about yourself? (self-esteem) } \\
\text { [Est-ce que vous se sentez bien dans votre peau? (estime de soi-même)] }\end{array}$ & $\begin{array}{l}\text { Always } \\
\text { Most of the time } \\
\text { Sometimes } \\
\text { Rarely } \\
\text { Never }\end{array}$ & $\begin{array}{l}4 \\
3 \\
2 \\
1 \\
0\end{array}$ & Gilborn et al. 2006 \\
\hline
\end{tabular}




\section{Reply to the referees' comments to the authors:}

We wish to thank the reviewers for their very useful and detailed comments and questions. Below we address all these comments and indicate the revisions we made to the manuscript in response to the reviewers' comments.

\section{Referee: 1}

\section{Comments to the Author}

The need to understand the differences between AIDS-orphans and other Orphans (due to other causes) is important particularly due to stigma/discrimination and depletion of family resources before death. As such this paper is a good attempt to contribute to this research gap and I commend the author(s). Also, being able to distinguish the three groups of children based on community perceptions' on the causes of parental deaths should be commended. Nonetheles. there are major issues with regard to the way the data was anlyzed. First, the orphans and AiDS-orphans groups were significantly different i.e. most of the $O$-A are double orphans and/or maternal orphans. Previous studies have shown that both Maternal-O and Double-O status have worse effects on children mainly because of lacking a nurturer (mother or adult caregiver), which affects their PSS. Therefore these fundamental differences between the two groups need to be controlled for before concluding that observed differences are actually because their parents died of HIV/AIDS. It will be useful to re-analyze the data to make sure that the differences are not due to these pre-existing differences.

All reviewers raised concerns about the fact that we did not control for observed differences in single versus double orphanhood among AIDS-orphans (O-A) and other orphans (O). Below we have sketched a causal graph that illustrates the hypothesized causal associations between orphan status (O / O-A), double versus single orphanhood and outcome variables.

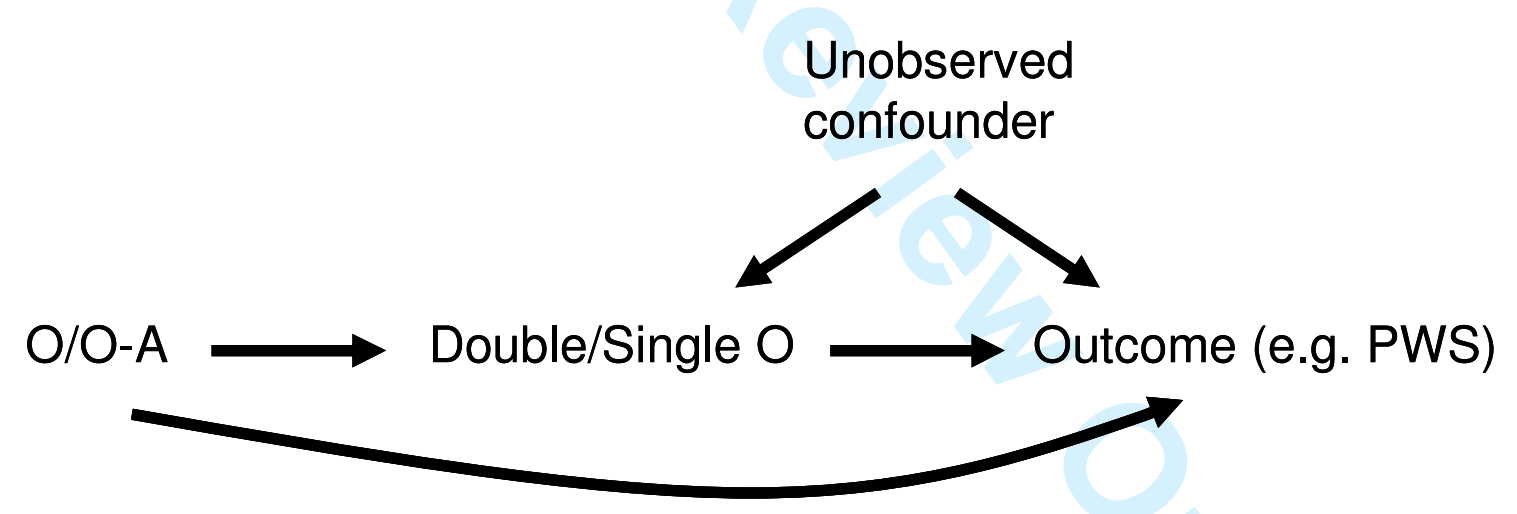

The first straight arrow indicates that double orphanhood is more likely among children orphaned by AIDS than among children orphaned by causes other than AIDS. This causal association can be explained by the fact that HIV is a sexually transmitted disease, increasing the likelihood that the remaining parent will die as well, given that the other parent has died of AIDS. The second straight arrow represents the effect that double versus single orphanhood has on the outcome variables under study. As pointed out by the reviewers, "double orphans" tend to be worse off than "single orphans". The curved arrow represents direct effects of the cause of parental death (AIDS versus non-AIDS) on the outcome variables. Controlling for double versus single orphanhood would only be relevant if it is assumed that there are no confounders of the causal association between double versus single orphanhood and the outcome variables, AND if one wants to investigate if there is a direct effect of orphan status, additional to the effect through double / single orphanhood. As we are mainly interested in the full effect that orphan status (O/O-A) has on outcome variables (so including the indirect 
effect that is mediated by double/single orphanhood), and not just on the direct effect, we did not need to control for double/single orphanhood. An advantage of the resulting analysis is that it is valid, even when there are confounders of the causal association between double versus single orphanhood and the outcome variables.

We suggest including the above explanation (without the causal graph) in the discussion section as we suspect that many readers will share the reviewers' concerns about not controlling for double versus single orphanhood:

"As we were mainly interested in the full effect that orphan status $(\mathrm{O} / \mathrm{O}-\mathrm{A})$ had on outcome variables (so including the indirect effect that is mediated by single/double orphanhood), and not just in the direct effect, we did not need to control for double/single orphanhood. An advantage of the resulting analysis is that it is valid, even if there were confounders of the causal association between double versus single orphanhood and the outcome variables (Cole \& Hernán, 2002)."

The follow references discuss in more detail the issue of controlling for variables that are on the causal pathway:

Rosenbaum, P.R. (1984), "The consequences of adjustment for a concomitant variable that has been affected by the treatment," Journal of the Royal Statistical Society Series A, 147: 656-666.

Cole, S.R., and Hernan, M.A. (2002), "Fallibility in estimating direct effects," International Journal of Epidemiology, 31: 163-165.

Second, the methodology is not clear on whether the key informants knew these children before or did they interview relatives/neighbors to find out; if so what criteria or open-ended question was used to classify children in these groups - $O$-A or $O$ - please clarity;

Referee 1 requested more clarity on the procedure and criteria used to classify children in the respective groups:

The key informants knew the children before and did not interview relatives or neighbours to find out where the children from the three groups ( $\mathrm{NO}, \mathrm{O}, \mathrm{O}-\mathrm{A})$ were staying.

After the interviewers were directed to the households by the key informants, a classification procedure was followed as detailed below:

The children between 10 and 18 years were asked what the cause of death of their parent(s) was. Their answers were then verified with the members of the household that the children were living in at the moment of the interview (care givers), as well as with neighbours and other members of the direct community that the household was situated in. In 20 cases, the views on the cause of parental death were conflicting and these cases were excluded from the analysis. If the child reported to not know the cause of death or refused to talk about the cause of death, and the information from members of the household that the child was living in at the moment of the interview, as well as with neighbours and other members of the community that the household was situated in, was unanimous, then this case was not excluded.

We have added the highlighted section in the methods section of the manuscript. 
In response to the question which of the groups was used as the reference category, we wish to clarify that the Non-AIDS orphans $(\mathrm{O})$ acted as the reference group, since we were particularly interested in the question whether differences in outcome variables existed between AIDS-orphans and Non-AIDS orphans. The PWS and other outcome variables among non-orphans can be assessed by looking at figures 1,2 and 3 as well as tables 2 and 3 . On average non-orphans scored better on all the outcome variables under study. However, the figures show that unfavourable outcomes were also observed in at least some non-orphaned children as well.

Conclusions made seem unjustified especially that OA live in a cycle of poverty and underdevelopment than other orphans - there is no finding in the paper that leads us to this conclusion.

We have revised the last paragraph of the discussion section so as to make the conclusions less general and closer to the strict interpretation of the research findings. Below we copied the revised paragraph:

In conclusion, our results suggest that the psychological health of children who are thought to be AIDS-orphaned is more threatened than that of other orphans. Additionally, AIDS orphans were significantly more likely to go to bed hungry than non-AIDS orphans in Guinea despite being much more involved in economic activities. Low psychosocial well-being scores and unfavourable socio-economic living conditions were also observed for at least some nonorphans and non-AIDS orphans. Comprehensive, non-discriminatory strategies involving all stakeholders in the fields of health and social development are therefore urgently needed.

\section{Referee: 2}

Comments to the Author

Overall, well-written and a subject worth highlighting in Guinea. Results are less dramatic or "important" internationally than they are for Guinea; maybe should consider strengthening the Guinea-specific angle (or the angle of "AIDS orphans" in a low-prevalence country). Should the background talk a little more about the situation in Guinea? Low prevalence = high stigma?

Referee 2 suggested to strengthen the article's angle of AIDS orphans in a low-prevalence country and the potential association between low prevalence and high levels of stigma. As far as we know, published data on HIV/AIDS-related stigma in Guinea is absent.

Further referee 2 wanted to know how hard it was to find people willing to admit to an AIDS death in the family, and whether there is a national program for OVC due to HIV. It was not easy for people to admit to an AIDS death in their family. However, in the majority of the interviews, the households were willing to cooperate because the team of interviewers were linked to local CBOs / NGOs that had built a bond of trust with the local community over time. The interviewers were respected members of the community and viewed as trustworthy. Each interview took more than one hour. In about one quarter of interviews, sensitive questions were initially ignored or answered in vague terms, and were only truly answered by the end of the interview, when a sense of trust and confidentiality had been established. 
The national strategic plan 2003-2012 has a specific section concerning the care for orphans and other vulnerable children. The programmes that are currently being implemented for OVC focus on providing schooling and nutrition to OVC. As briefly mentioned in the discussion section of the manuscript, a workshop was organized in September 2007 in Conakry, during which the research findings were presented and discussed in the attendance of representatives of local, national and international NGOs, donor organizations and the national commission for the fight against HIV and AIDS (CNLS). This workshop contributed the revised strategic plan for the 2008-2012 period, which puts greater emphasis on the importance of schooling for OVC, allocates greater financial resources to provide financial and nutritional support families to families that are taking care of OVC, and expresses the need for more studies to estimate the number of OVC in Guinea, to quantify their needs and to map the efforts that are being made to address these needs.

What does this tell Guinea that it didn't know? How will they use it? For advocacy? I think this might be truer to the true meaning of the findings than suggesting that they demonstrate something new and general about orphanhood due to AIDS.

\section{Other comments/questions:}

"Over the past decade, it has become clear that children of whom one or both parents are known to be HIV positive or have died of AIDS, are especially vulnerable. They bear more socio-economic hardship, are less likely to be at the proper education level, feel more frequently stigmatized and discriminated against and carry a heavier psychological burden."

Several questions about this sentence:

1. It seems to state as known fact what your study question proposes to investigate.

2. More vulnerable than who? It doesn't say. The sentence seems to want to say that "AIDS orphans" are more vulnerable than other orphans, but the following sentence makes it clear that we don't know this.

3. Are any of the cited studies from Guinea? Some of these issues (esp. stigma) would seem to be fairly specific to countries/cultures.

We have revised the second paragraph of the introduction section, in response to the comments of reviewer 2 (Cfr. below). None of the references are from Guinea. As far as we know, there have not been any scientific papers published on these issues in Guinea.

Over the past decade, it has become clear that children of whom one or both parents are known to be HIV positive or have died of AIDS, are especially vulnerable. They bear more socio-economic hardship, are less likely to be at the proper education level, feel more frequently stigmatized and discriminated against and carry a heavier psychological burden than children of parents that are alive and not affected by HIV/AIDS (Bauman, Foster, Silver, Berman, Gamble, \& Muchaneta, 2006; Cluver \& Gardner, 2007; Forehand, Steele, Armistead, Morse, Simon, \& Clark, 1998; Funkquist, Eriksson, \& Muula, 2007; He \& Ji, 2007; Lee, Detels, Rotheram-Borus, Duan, \& Lord, 2007; Nyamukapa, Gregson, Lopman, Saito, Watts, Monasch et al., 2008; Rotheram-Borus, Stein, \& Lin, 2001; Rotheram-Borus, Weiss, Alber, \& Lester, 2005; Strode \& Barrett-Grant, 2001). Most studies, however, have compared the plight of so-called AIDS-orphans with non-orphaned children only. 
Consequently, such study designs, which leave out a comparison group of children orphaned by causes other than AIDS, are unable to establish if the AIDS-related cause of death of the parent(s) confers effects additional to those of parent-bereavement (Wild, Flisher, Laas, \& Robertson, 2006).

"After having explained the study objectives to each candidate respondent, informed consent to participate in the survey was obtained from the child and one of his/her parents or foster care givers."

1. What were the study objectives? (The article seems to imply that these results were obtained as part of a broader study ("For this paper, we considered ...").

The findings reported in this manuscript are part of a larger study. The overarching objectives of this larger study were to assess the psychosocial well-being of AIDS orphans in Guinea, with non-orphans and non-AIDS orphans as comparison groups. In a second paper (in preparation), we focus on differences in social networks and social support received by the 3 groups of children. In addition, the second paper elaborates on the stigma and discrimination experienced by AIDS orphans.

The study was designed by a team of researchers from Ghent University and the directors of the local NGO FELICA. The fieldwork was coordinated by a junior researcher from Ghent University and the interviews were conducted by local research assistants. All research assistants received ad-hoc Communication Skills training and social support skills training, organized through the EU-commission funded AEDES project.

Referee 2 asked what, if any, incentives were offered for participation. The children received a toy bracelet, but were not informed about this gift until after the interview.

All households taking care of AIDS orphans were offered support (nutritional and educational) through the NGO FELICA. About $90 \%$ of them accepted this offer. Further, the coordinates and information of other households in need were passed on to a number of NGOs (after informed consent).

5. How many (in the various presumptive groups) refused to participate?

In total 39 households refused to participate: 2 cases in the NO group, 19 in the $O$ group and 18 in the A-O group. We added this information in the methods section of the manuscript.

Study sample is pretty weak: Small (for analysis by three or four groups); chosen from substantially different locations (including one with heavy NGO aid activity); lots of factors potentially interfering with clear conclusions. Selection open to all kinds of bias.

"The first category was comprised of children whose parents were still alive and not perceived to be HIV positive (NO)." Pretty loose criteria - could be almost anybody. No idea what this group might represent.

The intro talks about four study groups; the methods seem to talk about only three. 
We have corrected the error regarding the number of groups: the children were divided into three groups, not four.

Were the three or four groups equally represented in all geographic areas? (i.e. Conakry didn't have all the "AIDS orphans," for example).

The geographical distribution (Conakry, NZ and villages around NZ) was not significantly different in NO, O and O-A (Cfr. Table 1).

Didn't ask how long ago the parent died?

We did not ask how long ago the parent had died. In retrospect this would have been added useful information.

No analysis by age group?

The effect of age (as a continuous variable) was considered in all regression models. However, only in the model for sleeping commodity did age turn out to be independently associated with the outcome variable. Younger age was an independent risk factor for not having a bed or couch to sleep on (Cfr. Last paragraph of the results section).

"The proportion of children who had lost both parents (double orphans) was significantly higher among AIDS orphans than among the children orphaned by causes other than AIDS." - Did you try to control for this? Couldn't this (rather than the cause of death being AIDS) explain part of the differences you found? You should discuss this.

"Secondly, all analyses were based upon the perception of the community about the HIV status and/or cause of death of the children's parent(s)." Above you said that HIV status and cause of death were confirmed by families.

Why is it important to know about differences between "AIDS orphans" and other orphans? There's not exactly a contradiction but at least a tension between the study question and the conclusion: If we know we don't want to target orphans due to AIDS (to avoid stigma, etc.), why study the question of how they differ? At the least, the article should discuss why this question is important, what uses we might make of its findings. Why did you want to fill this research gap?

Our main conclusions are that O-A are worst off. But that there are also children from the other groups that are in need of support. Our findings might be used when designing or revising national strategies to address the consequences of the HIV epidemic, as well as strategies to improve children's health in general. As mentioned above, a second paper will show that stigma and discrimination is a major problem faced by O-A. Narrow-targeted support only for AIDS orphans might increase this problem.

Referee 3

Interesting paper and worthy of publication. Some specifics need to be incorporated. 
The differences between single parent bereavement and double parent bereavement is well taken. This data needs to be set out and actually analysed. The authors note that children who have both parents deceased are more likely to be in the AIDS Group - numbers need to be furnished and a statistical test carried out to conform this. This is a vital pre-requisite for publicaiton on this paper.

The fraction that is "double orphaned" is greater among O-A than among O. The size of this difference is shown in table 1 and a Pearson Chi-square test is performed $(\mathrm{P}=0.02)$ to assess the significance of this difference. The reader has all the information to infer the number of $\mathrm{O}$ and O-A that were double orphaned.

Next the author needs to note how limited their categorisation is (based on village heresay). Clearly the villagers would know if a parent has died. But would they know if it is AIDS Related? Given the vast literature on stigma and disclosure this is a severe weakness. Were teh village views validatead in any way, were more than one views taken(and what were the correlations). This needs to be set out clearly and mentioned as a limitation of the study.

This concern has been addressed in previous paragraphs in response to similar concerns raized by Referees 1 and 2 . 
Table 1. Socio-demographic characteristics of the sample population

\begin{tabular}{|c|c|c|c|c|}
\hline & $N O(n=140)$ & $O(n=133)$ & $\begin{array}{c}O-A \\
(n=124)\end{array}$ & P value \\
\hline Sex & & & & $0.29 *$ \\
\hline Female & 44.3 & 45.1 & 36.3 & \\
\hline Male & 55.7 & 54.9 & 63.7 & \\
\hline Mean age $(S D)$ & $13.5(2.5)$ & $13.9(2.4)$ & $14.0(2.6)$ & $0.09 \dagger$ \\
\hline Region & & & & $0.92 *$ \\
\hline Conakry & 50.7 & 49.6 & 45.2 & \\
\hline N'Zérékoré (NZ) & 27.9 & 28.6 & 30.6 & \\
\hline $\begin{array}{l}\text { Villages around } \\
N Z\end{array}$ & 21.4 & 21.8 & 24.2 & \\
\hline Religion & - & & & $0.08^{*}$ \\
\hline Muslim & 47.1 & 51.1 & 52.4 & \\
\hline Christian & 50.0 & 44.4 & 37.9 & \\
\hline Other & 2.9 & 4.5 & 9.7 & \\
\hline $\begin{array}{l}\text { Number of minors } \\
\text { in the household }\end{array}$ & & & & $0.08 *$ \\
\hline$<4$ & 12.1 & 13.5 & 7.3 & \\
\hline $4-6$ & 37.9 & 39.8 & 31.5 & \\
\hline $7-9$ & 27.1 & 18.8 & 23.4 & \\
\hline$>9$ & 22.9 & 27.8 & 37.9 & \\
\hline Head of household & & 80 & & $<0.001^{*}$ \\
\hline Parent & 80.0 & 51.5 & 30.3 & \\
\hline Grand parent & 3.6 & 14.4 & 12.3 & \\
\hline Extended family & 10.0 & 25.0 & 42.6 & \\
\hline Other & 6.4 & 9.1 & 14.8 & \\
\hline Maternal orphans & NA & 49.6 & 61.3 & $0.08^{*}$ \\
\hline Paternal orphans & NA & 75.2 & 82.3 & $0.22 *$ \\
\hline Double orphans & NA & 24.8 & 43.5 & $0.02 *$ \\
\hline
\end{tabular}

\footnotetext{
* Pearson's Chi-square test

$\dagger$ one-way ANOVA
} 
Table 2. Factors associated with the PWS $(n=385)$

\begin{tabular}{|lccc|}
\hline Predictor variable & Coefficient & $\mathbf{9 5 \%}$ CI & P value \\
\hline Category & & & $<0.001$ \\
\hline O (reference) & 0 & & \\
\hline NO & 2.5 & $1.7-3.4$ & $<0.001$ \\
\hline O-A & -1.6 & $-2.4--0.7$ & $<0.001$ \\
\hline Region & & & $<0.001$ \\
\hline Conakry (reference) & 0 & & \\
\hline N'Zérékoré & 1.4 & $0.6-2.2$ & $<0.001$ \\
\hline Villages around N'Zérékoré & 2.3 & $1.4-3.1$ & $<0.001$ \\
\hline Minors in the household & & & $<0.001$ \\
\hline$<4$ (reference) & 0 & & \\
\hline $4-6$ & -0.5 & $-1.8-0.8$ & 0.73 \\
\hline $7-9$ & -1.5 & $-2.9--0.1$ & 0.03 \\
\hline$>9$ & -2.1 & $-3.4--0.7$ & $<0.001$ \\
\hline
\end{tabular}


Table 3. Estimated adjusted (proportional) odds ratios for indicators of socio-economic hardship

\begin{tabular}{|c|c|c|c|c|c|c|}
\hline & $\boldsymbol{O}$ & NO & $95 \% C I$ & $O-A$ & $95 \% C I$ & $\begin{array}{c}\text { P value (type III sum } \\
\text { of squares test) }\end{array}$ \\
\hline School attendance & 1 & 2.95 & $1.61-5.39$ & 0.70 & $0.40-1.23$ & $<0.001$ \\
\hline Economic activity & 1 & 0.77 & $0.39-1.52$ & 3.04 & $1.45-6.36$ & $<0.001$ \\
\hline $\begin{array}{l}\text { Going to bed hungry } \\
\text { (daily) }\end{array}$ & 1 & 0.42 & $0.18-0.98$ & 2.73 & $1.24-6.02$ & $<0.001$ \\
\hline $\begin{array}{l}\text { No bed or couch to } \\
\text { sleep on }\end{array}$ & 1 & 0.45 & $0.20-1.05$ & 0.99 & $0.41-2.37$ & 0.02 \\
\hline
\end{tabular}




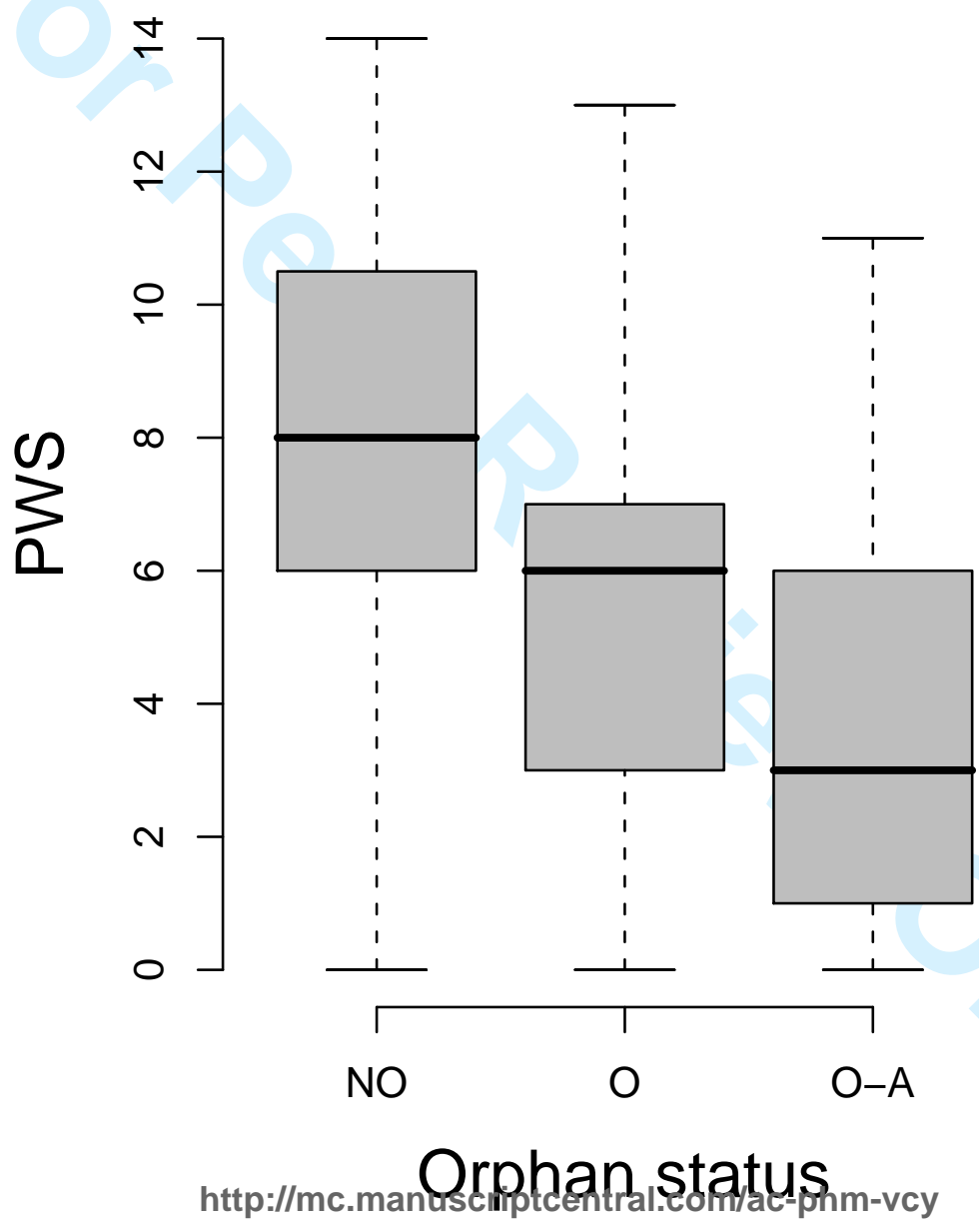



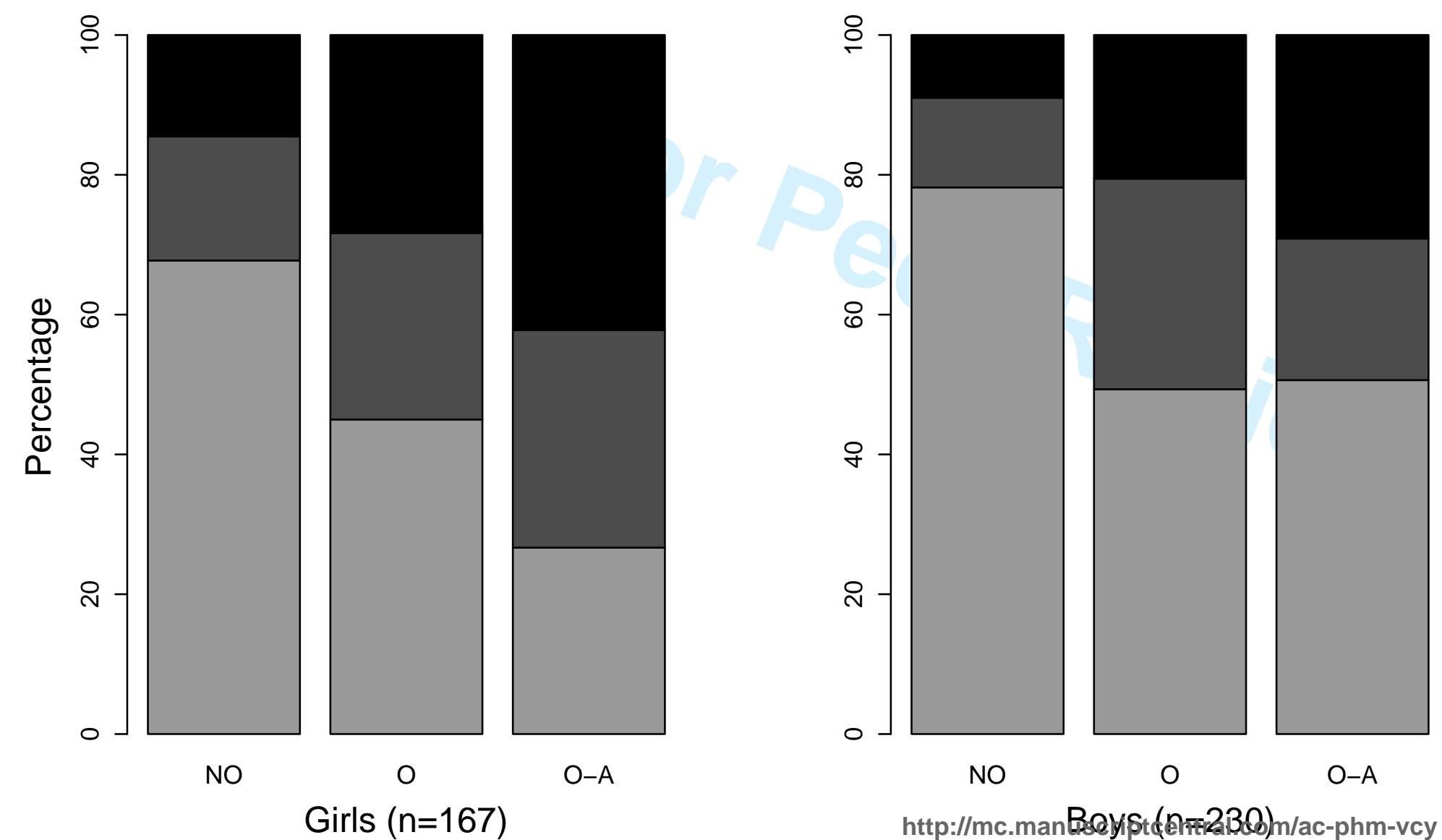

- No

$\square$ Sometimes

$\square$ Every day 

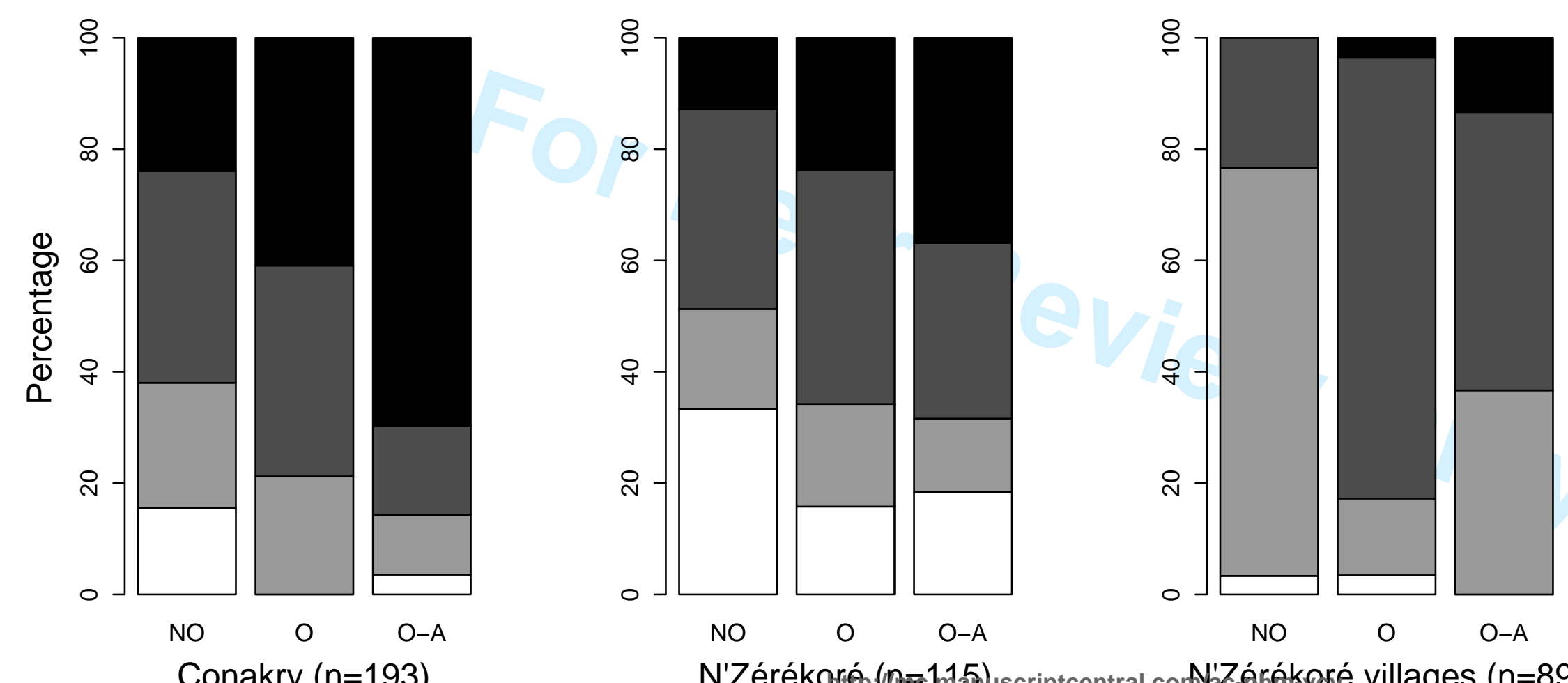

- Every day

Every week

Less than every week $\square$ Never

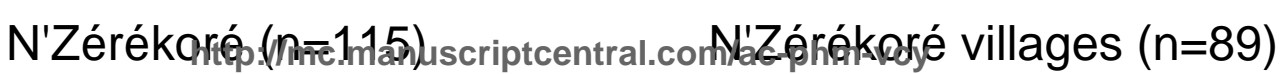

